This item was submitted to Loughborough's Research Repository by the author.

Items in Figshare are protected by copyright, with all rights reserved, unless otherwise indicated.

\title{
Sport brand ambassadors' experiences in sponsored user-generated branding programs
}

\section{PLEASE CITE THE PUBLISHED VERSION}

https://doi.org/10.1108/SBM-08-2019-0065

\section{PUBLISHER}

Emerald Publishing Limited

VERSION

AM (Accepted Manuscript)

\section{PUBLISHER STATEMENT}

This paper was accepted for publication in the journal Sport, Business and Management and the definitive published version is available at https://doi.org/10.1108/SBM-08-2019-0065.

LICENCE

CC BY-NC 4.0

\section{REPOSITORY RECORD}

Geurin, Andrea. 2020. "Sport Brand Ambassadors' Experiences in Sponsored User-generated Branding Programs”. Loughborough University. https://hdl.handle.net/2134/12937646.v1. 
Running Head: AMBASSADORS’ EXPERIENCES

Sport Brand Ambassadors' Experiences in Sponsored User Generated Branding Programs

Resubmitted to

Sport, Business and Management

April 15, 2020 


\begin{abstract}
Purpose: The purpose of this study was to develop an initial understanding of sport brand ambassador participants' experiences in sponsored user generated branding (UGB) programs to assist sport organizations in developing the most mutually beneficial brand ambassador programs possible.
\end{abstract}

Design/methodology/approach: Semi-structured interviews were held with six individuals who serve as brand ambassadors for various sport brands. Data were analyzed using qualitative thematic analysis.

Findings: Participants were intrinsically motivated to serve in brand ambassador roles. Their experiences were impacted by whether their personal expectations were met, perceived relationship with the brand, perceived value to the brand, and perceived amount of work involved. They reported the best aspects of participation were a sense of community and free products and/or discounts. The most challenging aspects included not wanting to come across as a marketer, self-inflicted pressure to perform a certain way for the brand, pressure to purchase products, and lack of clear communication from the brand.

Research limitations/implications: As this study was qualitative, the findings are unique to the participants and the brands they represent. Therefore, the findings may be used to guide other research and brands but are not generalizable.

Practical implications: Sport brands wishing to employ sponsored UGB strategies such as brand ambassador programs must set clear expectations for ambassadors, communicate regularly, and develop a sense of community with and among ambassadors.

Originality/value: This study contributes to the limited sport management research on sponsored UGB and offers theoretical and practical implications in the areas of sport marketing and branding. 


\section{Introduction}

Sport consumer brands such as equipment, apparel, and nutritional product manufacturers have increasingly turned to consumer-to-consumer marketing methods in recent years (Geurin and Burch, 2017). Many brands utilize 'brand ambassadors', or hand-picked everyday users of their products, to represent the brand amongst the general population (Carufel, 2019). Brand ambassadors differ from influencers or celebrity endorsers in that they are non-celebrity individuals who are passionate about a brand and therefore seek a connection with it (Crabb, 2019; Urbaniak, 2016). Brand ambassador programs vary in structure and do not follow one specific format, but they often involve a contract between the sport brand and the ambassador specifying the terms of the ambassadorship. They also often involve free products for the ambassador in exchange for promoting the brand via social media and at participatory sporting events such as road races or triathlons (Crabb, 2019; Urbaniak, 2016).

While research has clearly documented the effectiveness of brands' use of celebrity endorsers (Schouten, Janssen, and Verspaget, 2019), to date, scant research has been conducted on sport brand ambassador programs, which utilize non-celebrities and are thought to be much less expensive than using endorsers (Burmann, 2010). Popular press articles and marketing firms highlight challenges for ambassador programs based on anecdotal evidence, such as selecting the right ambassadors to help fulfill the organization's goals, not focusing on the emotional connection between the brand and its ambassadors, not properly scaling the size of the ambassador program, and not giving enough to ambassadors in return for their service (e.g., Aranguiz, 2018; Shindell, 2018), but research or news coverage of ambassadors' experiences is virtually non-existent. This points to a major empirical research gap on sport brand ambassador programs, as any information available about participants' experiences appears to be anecdotal at best. From a sport management perspective, it is critical to understand the perspectives of brand 
ambassadors, as this can assist brands in developing the most effective brand ambassador programs possible, and ones that are mutually beneficial for the brand and the ambassadors. If ambassadors are unhappy with their experience as an ambassador, it could have negative consequences for the brand via unfavorable word-of-mouth communication, for example (Miller, 2019). Therefore, the purpose of this study was to develop an initial understanding of brand ambassador participants' experiences in these programs in order to assist sport organizations in developing the most mutually beneficial programs possible.

One example of a sport brand ambassador program is running brand Saucony, which selects a team of male and female runners of varying ages and running abilities to form a brand ambassador group named the "Saucony Hurricanes" each year. These runners go through an application process, and if selected for the team, receive free running apparel, running shoes, and discounts in exchange for wearing Saucony apparel and shoes at road races, posting about the brand on their own blogs and/or social media, and being actively involved in their local running communities ("Saucony Hurricanes", 2018). Other sport consumer goods manufacturers such as adidas, lululemon, Nuun Hydration, Patagonia, and PowerBar have also used brand ambassador programs to promote their brands amongst sport participants and fitness enthusiasts. Burmann and Arnhold (2009) refer to these programs as user-generated branding (UGB), which they define as, "the strategic and operative management of brand related user-generated content (UGC) to achieve brand goals" (p. 66). UGC could consist of social media posts or comments, maintaining a blog or writing guest pieces for other blogs or news outlets, or distributing information that the ambassador has created in some other form. Burmann (2010) refers to programs in which UGC is overseen by a brand as sponsored $U G B$ since a manager within the brand organization develops the program and rules related to the UGC. 
Researchers have called on scholars to contribute to UGB research by focusing on the experiences and insights of ambassadors (Rehmet and Dinnie, 2013), the role of interactions between ambassadors/peers (Andersson and Ekman, 2009; Burmann, 2010), and identifying success factors for such programs from the brand's perspective (Burmann, 2010; Geurin and Burch, 2017). In a call for expanded UGB research, Burmann (2010) stated, "Future studies should work on identifying success factors for UGB program quality, as well as motivational drivers for UGB program participation" (p. 3).

Through semi-structured interviews with ambassador program participants, the findings of this study will add broadly to the limited academic literature on UGB as a marketing tool, and specifically to the almost non-existent literature on UGB within the sport management literature, and will offer insights that future researchers can utilize to advance this line of inquiry. Additionally, the findings will assist sport brands in better understanding ambassador perspectives, hopefully leading to the development, implementation, and/or strengthening of new or existing brand ambassador programs. The following section reviews literature focused on branding, UGB, and brand ambassador programs.

\section{Literature Review}

Branding is a strategy for businesses to establish a presence in the minds of buyers (Aaker, 1991). Traditional branding involves one-way communication between the brand and its customers, with brand-created messages distributed through channels such as television, radio, printed press, and outdoor advertising (Grzesiak, 2015). With the rise of technology and the digital disruption, however, "the Internet has upended how consumers engage with brands" (Edelman, 2010, p. 2), and utilizing only the traditional methods of branding is no longer sustainable. Edelman (2010) argued that evaluating brand choices and advocating for or against 
the brand(s) they purchase in an online space (e.g., via social media, message boards, online reviews, etc.) are hallmarks of consumers in the digital age. Therefore, in order to establish the strongest possible presence in the minds of consumers, brands must shift their focus from traditional branding methods (e.g., paid advertising) and give greater consideration to the channels they control (e.g., website, social media accounts) and the media coverage they earn (e.g., customer-created online content about the brand) (Edelman, 2010). This notion relates closely to the concept of user-generated branding, which is covered in depth in the next section.

\section{User-Generated Branding}

Burmann and Arnhold's (2009) concept of sponsored UGB served as a guide for this study. According to these researchers, there has been a shift in the power balance between brands and consumers, with brands viewed as having less authenticity while consumers have become increasingly empowered. The loss of brand authenticity stems from changes in the competitive brand environment, such as an increasing number of brands and consumer perceptions of parity amongst brands, which then leads to a decrease in brand loyalty (Burmann and Arnhold, 2009). In terms of consumer empowerment, they argued that this is driven by advanced information technology and interactive media, as these allow consumers to "initiate and partly influence brand-related communication processes and information flows" (Burmann and Arnhold, 2009, p. 4). The term "electronic word-of-mouth" (eWOM) has been used to describe consumers' use of online environments to share their thoughts about brands (Daugherty and Hoffman, 2014). Brands, however, have no control over the information communicated via eWOM, which removes an element of control in the brand's own branding process. Depending on the information shared, eWOM can actually harm a brand, as not all content posted by consumers is positive (Daugherty and Hoffman, 2014). 
As a result of the shift of power between brands and consumers, brands began encouraging consumers to create brand-related content in both online and offline spaces. In order to regain some control over brand-related word-of-mouth and eWOM communication, brands began employing programs and strategies in which they selected consumers to become "joint creators of brand meaning" (Burmann and Arnhold, 2009, p. 13). Within the academic literature, this strategy has been referred to by names such as 'vigilante marketing' (e.g., Muniz and Schau, 2007), 'open source brand' (e.g., Pitt et al., 2006), 'citizen marketers' (e.g., Huba and McConnell, 2006), and 'influencer marketing' (e.g., De Veirman et al., 2017). Burmann and Arnhold (2009) introduced the term 'user generated branding' because of its emphasis on brand management and UGC.

Sponsored UGB refers to programs in which the brand is involved in facilitating the creation of content (Burmann, 2010), as is the case with brand ambassador programs, and therefore this study focused on sponsored UGB. The only known study within the sport management literature to focus on the concept of UGB was an examination of six running brands' Instagram accounts and their use of UGC (Geurin and Burch, 2017), although this work did not focus on sponsored UGB. Still, the results from Geurin and Burch's (2017) work helped inform the current study, as they found that UGC, or brand-focused content created by the brands' consumers, was more popular with the brands' followers than the content generated by the brand itself. This echoed Burmann and Arnhold's (2009) assertion that consumers have become increasingly empowered and can potentially be more influential than brands. From a sponsored UGB perspective, it suggests that brand ambassadors have the potential to be extremely valuable to the brands they represent via their communication about the brand with their friends, followers, or consumers interested in the brand. 
Burmann (2010) highlighted the benefits of sponsored UGB programs as being cost efficient, allowing brands to trace consumer contact, and allowing brand managers to receive immediate feedback about the brand. In light of more brands employing sponsored UGB strategies via brand ambassador programs, the benefits such programs may provide, and calls for future research to examine UGB from different perspectives (Burmann, 2010; Geurin and Burch, 2017) a study focused on brand ambassador participant perspectives seemed necessary to expand our understanding of sponsored UGB. The limited literature available on sponsored UGB guided the study's methodological considerations, such as the choice to utilize semi-structured interviews as well as guiding the creation of interview questions. These aspects are detailed later in the paper.

The following section reviews the literature focused specifically on brand ambassador programs, much of which comes from the fields of tourism and hospitality management.

\section{Brand Ambassador Programs}

While research on brand ambassador programs appears to be largely missing from the sport management literature, some work has been published in the fields of tourism and hospitality management on this topic (e.g., Andersson and Ekman, 2009; Rehmet and Dinnie, 2013; Xiong et al., 2013). Some scholars focused their inquiry on organizational employees as brand ambassadors, also referred to as internal branding (Aurand et al., 2005). While the present study did not attempt to examine internal branding, some of the findings from these studies are relevant to the present line of inquiry. Xiong et al. (2013) examined the role of hospitality industry employees as brand ambassadors for their organizations, and concluded that it is important for employees acting as brand ambassadors to experience a meaningful connection to the brand in order to develop a long-term commitment to the brand. Further, Schmidt and 
Baumgarth (2018) reported that internal brand ambassador programs should encompass three attributes, including a goal orientation, a program that is organized and planned, and employees should have links to other employees from several different levels and departments within the organization. Programs with these attributes will help to foster the meaningful brand connection discussed by Xiong et al. (2013).

Other studies from the tourism industry are more closely aligned with the purpose of the current study. In their research on the perspectives of brand ambassadors for cities, regions, and countries, Andersson and Ekman (2009) echoed Burmann's (2010) identified benefits of UGB. They also identified four main motivations of participants in brand ambassador programs: gaining access to firsthand information about the place for which they served as an ambassador, being involved in marketing, attending meetings and events, and meeting new contacts and networking. They also found that motivations were different depending on how the ambassador was selected for participation in the program. Those who were appointed to the ambassador position without a formal application tended to view their ambassadorship as an honorary task, whereas those who actively sought the participation opportunity were more highly motivated to "help create a positive momentum for the place" (Andersson and Ekman, 2009, p. 50). Additionally, they concluded that ambassador programs created a "symbiotic co-branding situation" (p. 49) and were more effective than advertising.

Similarly, Rehmet and Dinnie (2013) studied brand ambassadors for the city of Berlin, and uncovered two categories of motivation amongst ambassadors: benefit-driven and altruistic. Some of the benefits that participants reported expecting from their participation included exposure in the news media for themselves or their businesses, and personal advantages through networking and interacting with other ambassadors in the program. Altruistic motivations 
included the desire to shift societal values in some way, participating because of civic pride, and a desire to represent the city of Berlin to the rest of the world.

The following section details the four research questions that resulted from gaps in the literature, as well as the method used to achieve the study's overall purpose of understanding sport brand ambassador participants' experiences in these programs in order to assist sport organizations to develop the most mutually beneficial brand ambassador programs possible.

\section{Method}

\section{Research Questions}

Based on the motivations and experiences uncovered from Andersson and Ekman (2009) and Rehmet and Dinnie (2013), the following research questions were developed:

RQ 1 - What motivates brand ambassadors to become involved in sport brand ambassador programs?

RQ 2 - What influences brand ambassadors' overall experience in sport brand ambassador programs?

Both Andersson and Ekman (2009) and Rehmet and Dinnie (2013) highlighted positive aspects of ambassadorship, such as tangible benefits, recognition by the public, and interactions with the brand's employees. They also reported negative aspects, such as a lack of collaboration between the brand organization and the ambassadors and disappointment from receiving little guidance regarding their role. Understanding that previous research uncovered both positive and challenging aspects to participation led to the creation of the final two research questions of this study, which were designed to better understand these aspects from sport brand ambassadors:

RQ 3 - What do brand ambassadors perceive to be the best aspects of their participation? 
AMBASSADORS’ EXPERIENCES 11

RQ 4 - What do brand ambassadors perceive to be the most challenging aspects to their participation?

\section{Procedures and Participants}

To answer the research questions and to achieve the study's purpose of developing an initial understanding of sport brand ambassador participants' experiences in sponsored UGB programs, one-on-one semi-structured interviews were held with six individuals who serve as brand ambassadors for various sport brands. Due to the lack of research in the area of sport brand ambassador programs and UGB, and because no known studies have examined ambassadors' perspectives specifically, it was unknown what the study might uncover. Therefore, questionnaires were deemed an inappropriate method, as it would be difficult to construct such an instrument given the lack of existing knowledge on the topic. According to Merriam and Tisdell (2016), semi-structured interviews allow "the researcher to respond to the situation at hand, to the emerging worldview of the respondent, and to new ideas on the topic" (p. 111), and this was deemed the most appropriate methodological tool for the study at hand. Semi-structured interviews allowed the researcher to ask follow-up questions and to probe more deeply on certain topics or issues that emerged in the interviews, thus generating a more complete picture of ambassadors' experiences than a questionnaire could.

Interviews were conducted either in-person or via phone, depending on the participant's location and availability. The exact number of sport brand ambassador programs that exist is unknown, therefore a purposive sampling method was utilized. As Merriam and Tisdale (2016) noted, purposive sampling requires the researcher to determine selection criteria. For this study, participants needed to meet the following criteria: 1) to be a brand ambassador for a sport-related product or brand, 2) the product/brand should be in a niche network (described in detail in the 
next sentence), and 3) the ambassador should use social media as part of their ambassadorship, as this was the only method utilized for identifying participants. "Niche networks" are described by Andersson and Ekman (2009, p. 46) as those which aim to generate a positive brand image amongst specialized groups of people (e.g., runners, yoga enthusiasts, etc.) through the use of ambassadors.

In order to recruit participants, the researcher first searched social media sites such as Instagram and Twitter for users who identified themselves as a brand ambassador for a sportrelated product or brand. When ambassadors who met the study's criteria were identified, the researcher attempted to recruit participants via email if a publicly available email address was identified on the social media account. When an email address was not present, the researcher contacted potential participants via social media such as personal messages on Instagram.

Following each interview, the researcher transcribed the interview verbatim, then took handwritten notes in a notebook regarding key details of the interview. Throughout the data collection process, interview transcripts and the notes for each interview were compared to the others that had already taken place in order to begin to identify keywords in the data (explained in greater depth in the Data Analysis section). While more than six ambassadors were invited to participate in the study, the researcher found that clear themes had developed after six interviews, and no new information was being gleaned, thus signaling a saturation point (Merriam and Tisdell, 2016).

Smaller sample sizes such as the one used in this study are not considered generalizable (Wimmer and Dominick, 2006), and generalizability is not the aim of qualitative research. The small sample size is acknowledged as a limitation of the study. The in-depth interview method, however, allowed the researcher to uncover rich data that will contribute to the limited scholarly 
understanding of sport brand ambassador programs from ambassador perspectives. According to Auerback and Silverstein (2003), when examining phenomena, qualitative research such as that utilized in this study often serves as the first step in building new knowledge.

Interviews took place between February 2017 and April 2017. Interviews were scheduled at times that were mutually agreeable between the participant and the interviewer. Interview questions were developed by the researcher with the concept of sponsored UGB and the research questions in mind. For example, one of the benefits of sponsored UGB according to Burmann (2010) was that brand managers could receive immediate feedback. Therefore, one of the questions on the interview guide was, "How often do you correspond with employees of the brand?" with a follow-up question of, "What does this communication consist of?" Participants were also asked what modes of communication were used if they did not specify this in their answer. The interview guide was reviewed by two sport management academics with experience conducting semi-structured interviews. The interview questions were approved by the researcher's institutional review board (research ethics committee), at which time the researcher began conducting interviews. Participants were asked questions relating to their participation in a brand ambassador program, including their motivations and perceived benefits and challenges of participation.

The interviews ranged between 20 minutes to 60 minutes in length, although only one interview lasted just 20 minutes, and the other five were between 45 to 60 minutes each. As previously mentioned, all interviews were transcribed verbatim by the researcher following the interview. Member checks (Krefting, 1991) took place in two phases. First, participants were given the opportunity to review their transcript and make any corrections or revisions they saw fit. No participants requested any changes to their transcript. Following data analysis, a second 
phase of member checks took place in which participants were sent a summary of results to review. If participants felt any portion of the analysis was incorrect or their interview had been taken out of context, they were invited to share this with the researcher. No participants voiced any opposition to the analysis, although many thanked the researcher for sharing the work. According to Kornbluh (2015), engaging participants in member checks helps to ensure that the researcher's personal biases do not impact the data analysis.

To protect each participant's privacy, pseudonyms were assigned. Table 1 presents the pseudonyms, basic information about each participant, and details of each participant's responsibilities as a brand ambassador based on the information given in their interview. $<$ INSERT TABLE 1 HERE $>$

\section{Data Analysis}

In order to analyze the data, a qualitative thematic analysis was conducted. This process identifies, analyzes, and reports on themes found within the data (Braun and Clarke, 2006). The analysis involved a two-stage coding process, in which the researcher first read through the transcripts multiple times, assigning keywords to the responses (Altheide, 1996; Miles et al., 2014). The researcher began the first stage of analysis while conducting the interviews, as described in the previous section. The second stage of coding involved grouping keywords established during first cycle coding and placing these into smaller themes (Miles et al., 2014). According to Braun and Clarke (2006), "A theme captures something important about the data in relation to the research question, and represents some level of patterned response or meaning within the data set" (p. 82). A priori themes were not developed due to the lack of existing data on sport brand ambassador programs. Keywords and themes, therefore, emerged throughout the data analysis process, which is described in greater detail below. 
In thematic analysis, it is essential that the researcher immerses him/herself in the data during the data analysis phase of the research (Braun and Clarke, 2006). Therefore, the decision was made to manually code all data for this study. First, the researcher read and re-read all transcripts. Next, the researcher utilized notebooks to write down the keywords as they were identified. The researcher used different colored highlighters to note different keywords within the transcripts. The researcher then studied the keywords and related sections of the interview transcripts in order to establish the themes. Once the themes were identified, the researcher utilized a peer debriefing process to further establish trustworthiness beyond the member checking procedures described in the previous section (Lincoln and Guba, 1985). These sessions were held with a sport management scholar independent of the study. These sessions involved the researcher describing their interpretations of the data, asking the peer debriefer questions about the clarity of the analysis, as well as the peer debriefer asking questions and at times offered a different perspective on some of the findings for the researcher to consider. The peer debriefing process allows the researcher to articulate and refine their interpretations of the data (Krefting, 1991) and can ultimately improve the results' accuracy (Creswell, 2014).

As a researcher's own personal characteristics and life experiences have the ability to impact data analysis in qualitative research, the author acknowledges that they served a one-year role as a brand ambassador for a sport apparel brand in 2013, which served as a catalyst for their interest in conducting this study. None of the participants from this study were brand ambassadors for the same brand as the author. Due to the researcher's personal experience with a brand ambassador program, they brought unique knowledge about such programs to the study, and attempted to minimize the potential for bias in data analysis via the use of member checks and peer debriefing, as described above. 


\section{Results}

The following section is organized based on the four research questions guiding this study. All themes identified within the data can be found in Table 2.

$<$ INSERT TABLE 2 HERE $>$

\section{Participation Motivations}

The first research question asked what motivates brand ambassadors to become involved in sport brand ambassador programs. Data analysis revealed three main themes for this research question. The first theme was free items. Many ambassadors indicated that they would use the brand's products regardless of whether they were an ambassador, so it was an enticing incentive to receive products for free or at a discount. For example, Greg said,

I'm sure this is probably the terrible thing most people say, but it was more just about free stuff. ... I was very pleased to actually not be spending my own money on shoes that otherwise I was going to purchase anyway.

Samantha explained that she was interested in her ambassador program because of the 55\% discount she received on the company's products, stating, "I had already found that I was regularly purchasing their [product] so I thought, 'Hey, if I'm doing that then I might as well get a discount.",

The second theme in terms of motivations was a feeling of pride or being special. Nearly all ambassadors reported being motivated by a sense of pride for their affiliation with the brand and knowing that they were representing the brand. Many ambassadors recounted feeling special for being selected for the brand ambassador program, and in many cases, being recognized by their peers for their affiliation with the brand. Phoebe, who had once been extremely competitive in running, and now considers herself to be more of a recreational runner, said, "Being able to 
talk about it is kind of cool, like there's a little bit of a pride factor of being like, 'Yeah, I'm still in the running community' even if it's on a small scale." Similarly, Bobby said that it was motivating for him to be able to tell other people that he was associated with the specific company he represented in his ambassador program, and Greg said,

You almost feel a little bit of pride, like, 'Hey, someone picked me to wear this' and you get your free stuff, but other people say, 'Well what makes him so special to get the free stuff?' and you think, well maybe that does say something. That's as good as winning a trophy in itself, and yeah, a little pride full of that.

Closely related to the feeling of pride or being special, the third motivation was affiliation with a brand that aligned with personal characteristics. Some ambassadors spoke about the aspects of the brand they represented that aligned well with their own personal characteristics. These similarities attracted some ambassadors to the brands they represent, as illustrated by Sarah, who said,

I would say I really like coffee and I feel like it fit me well because I use coffee to kind of fuel my athletic endeavors, so if there's kind of that partnership with whatever brand you're representing, then you can help each other out in that way. Phoebe discussed her experiences with running groups that seemed cliquey, and her desire to be part of a more open-minded running group. Her ambassador program included a running group aspect, and she said of it, "This group seemed different because they seemed more authentic, a little more open and accepting ... they're more open in the way I would want to be open with a run group." Ambassador Experiences 
The second research question sought to understand what factors influence ambassadors' overall experiences in sport brand ambassador programs. Some ambassadors reported being very pleased with their participation, while others were left unsatisfied and therefore, had a less fulfilling experience. Data analysis revealed four key factors that impacted participants' experiences. The first was whether personal expectations were met. While some ambassadors reported having very few expectations when starting their ambassador program, others seemed to have preconceived notions of what participation would entail. For those who had few expectations from the start and their expectations were met (or exceeded), their experience in the program seemed much more positive than those who felt their expectations were not met. One such ambassador was Bobby, who was disappointed with the amount of merchandise and benefits he received from his program. He said,

For running and trail running it's like 'cool' to have sponsorships, and I think people like to say that because it gives them clout and stuff almost, and these companies know that going in, so they also know that they don't actually have to do anything or give you anything.

Conversely, Greg had low expectations for his program and overall seemed much more pleased with his participation. Greg said,

There's nothing lost [by participating]. You're going to participate [in road races] anyway, and it didn't really bother me wearing someone else's name on your shirt or agreeing to any of the terms of it and I was very pleased to not actually be spending my money on shoes that otherwise, I was going to purchase anyway. The next factor in determining an ambassador's experience with the program was their perceived relationship with the brand. Those ambassadors who reported feeling a close 
relationship with the brand and its representatives/employees also appeared to be more satisfied with their overall brand ambassador experience, as illustrated by Phoebe, who said,

I feel so connected (to the brand) and can email them and say, 'Hey, I thought you might be really interested in this trip that I took my students on with the college that I work for this past week into the desert' and they respond within a couple of hours like, 'That's so cool! Can we feature that?' So yeah, I think that personal benefit is kind of a benefit that works for me.

Similarly, Kent spoke often about his relationship with the brand and the sense of community he felt with the brand and other ambassadors. He said, "I just like the small-town feel of it. The community of these guys. Everything's pretty cool with them."

The third factor was the ambassador's perceived personal value to the brand. While the previous factor dealt with the ambassador's perceived relationship with the brand, this factor was different in that it centered on the extent to which the ambassador felt they were valued by the brand. It is possible to have a kind and/or friendly relationship with a person or a brand, yet not feel that one is highly valued by that person or brand. The ambassadors who felt the brand truly valued them and their participation in the ambassador program reported having a more positive experience than those who did not perceive the brand to value them personally. Samantha discussed her communication with other ambassadors and reported that the brand listened to their suggestions, sometimes implementing them. She said,

People make suggestions on our group page all the time, like, 'Oh, we need colors for this' or 'Let's do Olympic colors since LA is in the running for the Olympics', so it's sort of a fun thing to feel involved. People always like to feel like they're 
part of the creation of something. So, in that sense, it makes me feel more personally invested in the company itself.

Bobby had a different perspective, saying, "They just want to make money at the end of the day. The community-building and the camaraderie is just another way to get people hooked."

Finally, the fourth factor uncovered from data analysis was the perceived amount of work involved. Some ambassadors reported feeling overwhelmed or confused at times about the work they were expected to do as part of their ambassadorship, while others said that the brand's expectations of them were minimal and did not impinge on their day-to-day routine or lifestyle. Those who felt their workload was minimal tended to report more satisfaction with their ambassador program participation, as was the case for Sarah, who said,

For me, it's just that, it's an easy, good partnership that isn't too overbearing or time-commitment heavy, so I feel like if I can help the brand and then get, you know, if they can give me a few products, it's a good thing.

Similarly, Samantha described her ambassador program as low-stress, saying, "I feel like they're allowing me to just live my life and wear the socks for fun ... and they don't have as much of an expectation for me to actually get their product sold."

\section{Best Aspects of Participation}

Once an understanding of the participants' overall experiences in an ambassador program, including the factors that influenced that experience, was developed, the third and fourth research questions sought to create a deeper understanding of the best and most challenging aspects of ambassadorship. The third research question asked what brand ambassadors perceived to be the best aspects of their participation in a brand ambassador 
program, and two themes emerged. The first was a sense of community, which most participants reported feeling with either the brand or the other ambassadors in the program, or both. Based on the interview data, including the amount of detail the ambassadors provided regarding this theme, as well as the tone of their voices when discussing it, this appeared to be one of the greatest perceived benefits to participating in a brand ambassador program. In an excited and inspired tone, Kent said,

Feeling like you're part of a team, feeling like you're special sort of ... having a reason to hang out early before the race and after the race to chat with people and try to get them to sign up. Running is such a weird community. Everybody that does it is a nut and loves it and they always want to talk about it. They want to talk about the next race, they want to talk about the new medal, they want to talk about everything, so it's kind of cool.

Similarly, Phoebe's tone of voice changed and seemed to become more thoughtful and heartfelt as she described how community was an important aspect to her ambassador participation: What I've always been drawn to is that community idea, of having a network of people who want to support you and do want to check in on you. You know, I'll get an email every now and then to be like, 'Hey, how's it going? Did you get that goal yet? How's your training going for this particular race?' And that, to me, is a much greater benefit than just receiving a box of goodies every couple months. While most participants enjoyed the sense of community they felt through their participation, all ambassadors reported enjoying the free products and/or discounts they received on the brand's products through their participation in the program. As Bobby said, "The discount is the best part. And you know, it is helpful to just be able to say that you are sponsored by 
multiple things because if you do good at races people kind of look for that, too." Sarah also reported enjoying the free products that came with her ambassador participation, saying,

I mean, I like coffee, so free coffee is always nice. I'm just being honest. The thing is, I tend to already, I get out there and I do adventurous stuff as much as I

can, so it's not a matter of, 'Oh, it gets me outside more' because I already go outside a lot. So, I would just say that it's like an added perk to get some free products for myself!

\section{Challenging Aspects of Participation}

The fourth and final research question sought to understand the challenges associated with being a brand ambassador participant, and four major themes emerged from the data. The first was not wanting to come across as a marketer or salesperson. Every ambassador involved in this study reported some uneasiness with the way they may be perceived by others as a result of their participation. Ambassadors found it challenging to find the balance between promoting the brand and being perceived as a marketer or salesperson. Sarah said, "Sometimes I just feel like I'm a marketing person or something, and I hate being that, like a marketing person to friends or whoever, and so I feel a little bit forced to post about a brand or whatnot.” Bobby echoed these concerns and described his personal philosophy as a result of feeling pressure to be a marketer, saying,

I won't be that person that automatically suggests whatever company I'm sponsored by at the time regardless of what the person's asking. I don't want to be that person. I just won't shamelessly self-promote ... and make these claims up about what shoes I was wearing or what the shoes did for my time in a race or whatever. 
The second challenge was self-inflicted pressure to perform a certain way for the brand. Similar to the previous theme, almost every ambassador reported feeling self-pressure to perform well in races/athletic events when they were representing the brand. None of the ambassadors reported the brands placing this pressure on them, and instead said that it was self-inflicted. Greg illustrated this, saying,

If you were having a bad race you were just kind of, 'Oh, I'm wearing this shirt. I hope [shoe store owner]'s not here and sees me running slow.' You know, the only pressure is really put on by yourself. There's no one really saying, 'I can't believe this guy's running slow and I gave him this sponsorship.' So, all the challenges and any negativity are brought on by myself, I'd say.

Phoebe echoed this challenge, saying she has felt:

a little bit of that pressure even though it's not very often that we're required to go to races. There is that idea that you do want to give back and be like, 'Look, I got this course record and it's really cool and I was wearing your singlet, which is even cooler.' You know, you do want to have that little bit of a give-back to them other than just talking about it.

Another challenge experienced by brand ambassador participants was the pressure to purchase products, as some ambassadors also felt an obligation to purchase the brand's products, even when they did not necessarily need the products. This theme is illustrated through Samantha's quote below:

Do I need to buy the sock of the month every month? Do I have to have every new color pattern that comes out? Am I allowed to, is it okay if I just hold tight and don't purchase any more? I mean, I have over 30 pairs of socks now. I could 
really go for a whole month wearing a different pair every day, and that's more than enough, really.

Finally, the fourth challenge identified via the data analysis was a lack of clear communication from the brand. This was not a challenge for all participants, but it seemed to be a serious challenge for others. Participants' reported communication issues ranged from a lack of communication regarding the brand's expectations for them as an ambassador, to a lack of communicated benefits of the ambassadorship, to a lack of providing a clear answer to straightforward questions asked by the ambassador, as demonstrated by Bobby, who described what happened when he inquired with the brand about continuing his ambassadorship: The thing that really irked me is that they would never give you a straight answer, they wouldn't say no. They'd just try to keep stringing you along, like, 'Well, you know, let's reevaluate in three months when the next business cycle is up' and they just keep saying stuff like that over and over again.

Kent also illustrated this theme, discussing the last-minute nature of communication from the brand to ambassadors, saying,

Sometimes information doesn't get disseminated fast enough and there's lastminute things or changes that are irritating. Sometimes they're like, 'You didn't get the email?' Like, 'No.' 'Oh, we didn't send it, we totally forgot.' There are issues that get irritating.

The following section discusses the findings in greater depth and reveals insights about how brands can use the information from this study to develop more effective and mutually beneficial brand ambassador programs.

\section{Discussion}


This research served as one of the first known studies on sponsored UGB within the field of sport management and sought to develop an initial understanding of sport brand ambassador participants' experiences in such programs via the use of in-depth interviews with ambassadors. The study was guided by the concept of sponsored UGB (Burmann and Arnhold, 2009) and the increasing need for brands to cultivate relationships with consumers in order to facilitate positive consumer-to-consumer communication related to the brand. The findings uncovered valuable information relating to brand ambassadors' experiences, including their motivations, benefits, and challenges of serving in this role. This section discusses the major findings in greater depth, offering insights on both the contributions to the academic literature on this topic as well as the practical implications for sport brands.

\section{Ambassador Motivations}

The first finding worthy of discussion is the ambassadors' reported motivations for participating in brand ambassador programs, which differed from previous research on ambassadors, and therefore contribute new knowledge to the brand ambassador literature within sport management. Ambassadors' reported motivations included: 1) free items, 2) a feeling of pride or being special, and 3) affiliation with a brand that aligned with personal characteristics. Obviously, free or discounted products would be attractive to most people, and feeling a sense of pride or being special is good for the ego, but brand ambassadors must also be willing to engage in activities such as promoting a brand on social media or representing the brand at a certain number of events. Therefore, for a brand ambassadorship to be considered worthwhile, the perceived value of the program's benefits must outweigh the perceived effort required to fulfil the ambassador's responsibilities. 
While the first and second motivations listed above appear to fit into Rehmet and Dinnie's (2013) “benefit-driven" category of motivations, none of the motivations in this study fit the altruistic category. Instead, the second and third motivations arguably served as intrinsic motivations, as they were driven by rewards experienced internally by the ambassadors. None of the motivations uncovered in this study aligned closely with those identified by Andersson and Ekman (2009) in their research on city/region/country ambassadors. These findings illustrate a difference between sponsored UGB participant motivations from the sport industry and the tourism industry, and point to intrinsic motivation as an important factor for sport-related UGB. Further research on sport brand ambassadors is necessary to confirm whether these findings are consistent across larger sample sizes.

\section{Marketing and Branding Implications}

While traditional branding strategies have been well documented within the sport management literature (e.g., Gladden and Funk, 2002; Gladden et al., 2001; Hardy et al., 2012), a fundamental shift has occurred in sport marketing, in which consumers' voices and messages can be just as powerful, if not more powerful, than those of the brand (Burmann and Arnhold, 2009; Geurin and Burch, 2017). UGB and the use of brand ambassadors are examples of the changing nature of branding, and this study's findings highlighted the importance of brands developing a relationship with their consumers beyond traditional mass branding methods. As ambassadors themselves are everyday consumers, they serve as a key group with which brands must develop a positive relationship. The strength of this relationship will be reflected in the ambassadors' communications with other consumers and potential consumers. One finding that could assist brands in ensuring they develop a positive relationship with ambassadors was that brand ambassadors were uneasy with feeling like a marketer or salesperson through their role as 
an ambassador. This highlighted the need for ambassadors' brand-related communication to appear authentic and organic. If ambassadors do not believe they are communicating to audiences in an authentic manner, a level of unease with their ambassadorship exists, which could have negative consequences such as discontinuing their ambassadorship, not posting as much about the brand on social media, or not fulfilling all of the requirements of their ambassadorship. These, in turn, would also result in negative consequences for the brand(s) they represent. It is incumbent upon the brands to offer support in the form of training or tips that will assist ambassadors in developing authentic messages. From a theoretical perspective, this tension between the brand ambassadorship and feeling like a salesperson represents a challenge of sponsored UGB not previously identified in the literature. Future research should attempt to better understand this tension, such as its source and its impact on the relationship between an ambassador and a brand.

Underscoring the importance of a brand's relationship between itself and its consumers was the finding that ambassadors' perceived relationship with the brands was of great importance to their overall experience with the ambassador programs and their personal views on the brands. This points to a second fundamental shift in sport marketing, in which the relationship between a brand and its consumers has the potential to influence consumers' choices as well as their brand-related eWOM to other potential consumers. As Edelman (2010) stated, discussing brands in online spaces is a hallmark of today's consumers, therefore the relationship a brand has with its consumers is vitally important to its success.

Along with the increased power of consumers' voices and the importance of a relationship between a sport brand and its consumers, an additional point that arose from this study was the idea that sport marketing has become increasingly complex. The ambassadors in 
this study understood that any of their communication appearing as "marketing" would be a potential turn-off to their audiences. While a clever, witty, or visually attractive advertisement on television might have been sufficient for capturing customers in the past, this study indicated that in order for today's marketing to be successful, it should not appear as "marketing". Creating messages that appear authentic and developing meaningful relationships with consumers are two incredibly important, yet difficult and time-consuming necessities for successful sport branding in today's sport business landscape. They represent a complex shift from traditional notions of sport branding.

\section{Sponsored UGB Implications}

Based on the interviews with the six ambassadors included in this study, it appeared that brand ambassador participants in sponsored UGB programs tended to self-select ambassador programs based on their own personal needs and characteristics, which indicates that serving as an ambassador is related to one's personal identity. Participants reported selecting brands whose values aligned with their own or with brands that could provide free or discounted goods/gear that the participant would purchase regardless of the ambassadorship. Brands that can clearly articulate and illustrate their brand values when soliciting ambassadors are likely to draw a pool of applicants that align closely with the brand's values. As one's role as 'ambassador' will contribute to their personal identity, a stronger connection between a brand's values and the ambassador's values will likely lead to a more engaged and passionate ambassador. Having ambassadors who are highly identified with the brand and whose values closely align with those of the brand might also assist in ensuring ambassadors are actively engaged and involved in the brand's activities, and that they project an image closely aligned with that of the brand when communicating with potential consumers. 
The results of this study point to the importance of a mutually beneficial relationship between the brand and the ambassador in sponsored UGB programs. Of those ambassadors who described a mostly positive experience with the brand, their expectations were met or exceeded and they felt a strong sense of community with the brand. Of those who experienced some level of dissatisfaction, communication from the brand was lacking, expectations were unclear, or expectations for the experience were unmet. This mirrored the findings of both Andersson and Ekman (2009) and Rehmet and Dinnie (2013), who found that brand ambassadors were disappointed when they received little guidance from the brand. Ambassadors revealed that creating a strong relationship between the ambassador and the brand was key to their satisfaction. This echoed Xiong et al.'s (2013) assertion that a meaningful connection is necessary for ambassador buy-in. Additionally, the ambassador must receive benefits that are perceived to be valuable enough to warrant the time or financial commitments they make as part of the program. Finding this balance could be challenging for brands that wish to employ sponsored UGB strategies, but it will benefit them in the long-run to have ambassadors whose experiences in the program are overwhelmingly positive.

Brands can accomplish a mutually beneficial relationship from their end by setting clear expectations for the ambassador from the beginning of the program, which will lay the groundwork for ambassadors as they navigate their way through the program. It is incumbent upon the brands to clearly communicate what the ambassador should expect from their participation in the program from the beginning, including the benefits to be received, the work that must be done on the ambassador's part, and the estimated amount of time it will take an ambassador to fulfill these commitments. This will help to avoid confusion or 
miscommunications, which may lead to feelings of resentment or dissatisfaction with the program, as illustrated by some of the ambassadors who participated in this study.

Additionally, ambassadors who developed a strong sense of community with the brand and/or other ambassadors in the program reported having a more fulfilling ambassadorship experience. This sense of community relates to one's social identity, or the sense of belonging one has to the social world (Tajfel, 1979). According to Tajfel (1979), a strong sense of social identity can positively impact one's self-esteem, which may lead to greater confidence and motivation among brand ambassadors to engage in ambassador activities. In order to foster this positive social identity, brands should engage in efforts that contribute to a sense of community with and amongst the ambassadors via regular communication. This will also assist in making ambassadors feel that they are valued by the brand. As ambassadors are often spread far apart throughout the country or the world, this can present a communication challenge for brands. Clear expectations and consistent communication can help to foster a deeper sense of engagement between the ambassador and the brand, and it is thought that those ambassadors with a higher level of engagement will ultimately be more satisfied with their participation in the program and will bring greater benefits to the brand. To develop a strong sense of community within the group of ambassadors, and further contribute to ambassadors' sense of social identity with the group, brands should create private ambassador-only groups/pages on social media sites or ambassador message boards where ambassadors can communicate with each other.

Finally, it is suggested that brands wishing to employ sponsored UGB programs ensure that they have a dedicated employee or team of employees who can devote a great deal of their time to managing the program.

\section{Conclusion}


The aim of this study was to develop an initial understanding of brand ambassadors' experiences in sport brand ambassador programs to assist sport organizations in developing the most mutually beneficial brand ambassador programs possible and to help guide future research on this topic. The findings offer preliminary insights into the area of sponsored UGB within the sport industry, offer practical implications for sport brands, and provide a strong foundation upon which to conduct additional sponsored UGB research on brand ambassador programs that will yield deeper insights and implications.

Specifically, this study found that ambassadors are motivated by product benefits and intrinsic reasons, and their experiences are impacted by factors relating to their personal expectations for the ambassadorship, whether they feel valued, and whether the benefits of the ambassadorship were worth the required work. A strong sense of community with the brand and/or other ambassadors as well as the benefits offered by the program contribute to ambassadors' positive feelings towards a program. Meanwhile, the challenges for ambassadors include various pressures placed on the ambassador by him/herself as well as those felt by the brand, along with a fear of appearing like a marketer and lack of communication from the brand. These findings presented a picture of ambassadors' experiences in brand ambassador programs, although the small sample size of this qualitative work is acknowledged. The study serves as an initial exploration on the topic, and helps to set a research agenda for more in-depth explorations into brand ambassador programs. Qualitative work is typically not generalizable, so the findings from this study are unique to the participants and brand ambassador programs these participants represent. The findings from this study should be used to conduct a larger-scale study that attempts to examine a larger sample through the use of questionnaires in order to enhance the 
generalizability of our knowledge of sport brand ambassadors participating in sponsored UGB programs.

Additionally, a host of future research opportunities stem from the findings of this study. First, while this study uncovered the experiences of brand ambassadors, additional research should attempt to interview brand managers who oversee ambassador programs to gain a stronger understanding of their goals for such programs, as well as the ways in which these programs are managed from an organizational standpoint. Similarly, future research should also attempt to understand consumers' perspectives on the sponsored UGB they consume from brand ambassadors. Insights on consumer perspectives would allow brands to better understand how their ambassadors' UGB efforts were received by the target market and to evaluate the perceived authenticity and effectiveness of their ambassadors' sponsored UGB messages.

Future research may also choose to focus on the differences in ambassador program structures and to develop a best practices guide regarding ambassador program structure for different types of sport organizations. Next, researchers could attempt to develop an evaluation mechanism by which brands could systematically evaluate their sponsored UGB programs and their effectiveness. Attempting to evaluate the effectiveness of such programs could assist brands in developing programs that are most effective in achieving their brand goals as well as providing the most optimal experience possible for their ambassadors. 


\section{References}

Aaker, D. (1991), Managing Brand Equity, Free Press, New York, NY.

Altheide, D.L. (1996), Qualitative Media Analysis, Sage Publications, Thousand Oaks, CA.

Andersson, M. and Ekman, P. (2009), “Ambassador networks and place branding”, Journal of Place Management and Development, Vol. 2 No. 1, pp. 41-51.

Aranguiz, A. (2018), “9 questions for a successful brand ambassador program”, available at: https://www.socialseeder.com/blog/9-questions-to-create-a-successful-brandambassador-program-2/ (accessed 5 January 2020).

Auerback, C.F. and Silverstein, L.B. (2003), Qualitative Data, NYU Press, New York, NY. Aurand, T.W., Gorchels, L. and Bishop, T.R. (2005), "Human resource management's role in internal branding: An opportunity for cross-functional brand message synergy", Journal of Product and Brand Management, Vol. 14 No. 3, pp. 163-169.

Braun, V. and Clarke, V. (2006), "Using thematic analysis in psychology”, Qualitative Research in Psychology, Vol. 3 No. 2, pp. 77-101.

Burmann, C. (2010), “A call for 'user-generated branding"”, Journal of Brand Management, Vol. 18 No. 1, pp. 1-4.

Burmann, C. and Arnhold, U. (2009), User Generated Branding: State of the Art Research, Gabler Verlag, Wiesbaden, Germany.

Carufel, R. (2019), "Sports influencer marketing is taking off - here's the play-by-play", available at: https://www.agilitypr.com/pr-news/public-relations/sports-influencermarketing-is-taking-off-heres-whats-happening/ (accessed 5 January 2020). 
Crabb, K. (2019), “Brand ambassador program blueprint”, available at: https://powerdigitalmarketing.com/blog/brand-ambassador-program-blueprint/\#gref (accessed 5 January 2020).

Creswell, J.W. (2014), Research Design: Qualitative, Quantitative, and Mixed Methods Approaches, $4^{\text {th }}$ ed., Sage Publications, Thousand Oaks, CA.

Daugherty, T. and Hoffman, E. (2014), “eWOM and the importance of capturing consumer attention within social media", Journal of Marketing Communications, Vol. 20 No. 1/2, pp. 82-102.

De Veirman, M., Cauberghe, V. and Hudders, L. (2017), "Marketing through Instagram influencers: The impact of number of followers and product divergence on brand attitude”, International Journal of Advertising, Vol. 36 No. 5, pp. 798-828.

Edelman, D.C. (2010), "Branding in the digital age: You're spending your money in all the wrong places", available at: https://saberfazer.net/wp-content/uploads/2011/10/Brandingin-the-Digital-Age.pdf (accessed 4 August 2019).

Geurin, A.N. and Burch, L.M. (2017). "User-generated branding via social media: An examination of six running brands”, Sport Management Review, Vol. 20 No. 3, pp. 273284.

Gladden, J.M. and Funk, D.C. (2002), "Developing an understanding of brand associations in team sport: Empirical evidence from consumers of professional sport", Journal of Sport Management, Vol. 16 No. 1, pp. 54-81.

Gladden, J.M., Irwin, R.L. and Sutton, W.A. (2001), “Managing North American major professional sport teams in the new millennium: A focus on building brand equity", Journal of Sport Management, Vol. 15 No. 4, pp. 297-317. 
Grzesiak, M. (2015). “E-branding vs. traditional branding”, Modern Management Review, Vol. 22 No. 4, pp. 89-100.

Hardy, S., Norman, B. and Sceery, S. (2012), "Toward a history of sport branding”, Journal of Historical Research in Marketing, Vol. 4 No. 4, pp. 482-509.

Huba, J. and McConnell, B. (2006), Citizen Marketers: When People are the Message, Kaplan, Chicago, IL.

Kornbluh, M. (2015), “Combatting challenges to establishing trustworthiness in qualitative research", Qualitative Research in Psychology, Vol. 12 No. 4, pp. 397-414.

Krefting, L. (1991), "Rigor in qualitative research: The assessment of trustworthiness”, The American Journal of Occupational Therapy, Vol. 45 No. 3, pp. 214-222.

Lincoln, Y.S. and Guba, E.G. (1985), Naturalistic Inquiry, Sage Publications, London.

Merriam, S.B. and Tisdell, E.J. (2016), Qualitative Research: A Guide to Design and Implementation, $4^{\text {th }}$ ed., Jossey-Bass, San Francisco, CA.

Miles, M.B., Huberman, A.M. and Saldana, J. (2014), Qualitative Data Analysis: A Methods Sourcebook, $3^{\text {rd }}$ ed., Sage Publications, Los Angeles, CA.

Miller, J. (2019), "Yes, your disgruntled employees are brand ambassadors, too", available at: https://www.scribewise.com/disgruntled-employees-brand-ambassadors-too/ (accessed 5 January 2020).

Muniz, A.M. and Schau, H.J. (2007), "Vigilante marketing and consumer-created communications", Journal of Advertising, Vol. 36 No. 3, pp. 35-50.

Pitt, L.F., Watson, R.T., Berthon, P., Wynn, D. and Zinkhan, G. (2006), “The penguin's window: Corporate brands from an open-source perspective", Journal of the Academy of Marketing Science, Vol. 34 No. 2, pp. 115-127. 
Rehmet, J., and Dinnie, K. (2013), “Citizen brand ambassadors: Motivations and perceived effects", Journal of Destination Marketing \& Management, Vol. 2, pp. 31-38.

“Saucony Hurricanes.” (2018), available at: http://blog.saucony.com/saucony-hurricanes-2018/ (accessed 4 August 2019).

Schmidt, H.J. and Baumgarth, C. (2018), "Strengthening internal brand equity with brand ambassador programs: Development and testing of a success factor model", Journal of Brand Management, Vol. 25, pp. 250-265.

Schouten, A.P., Janssen, L. and Verspaget, M. (2019), “Celebrity vs. influencer endorsements in advertising: The role of identification, credibility, and product-endorser fit", International Journal of Advertising, advance online publication.

https://doi.org/10.1080/02650487.2019.1634898

Shindell, B. (2019), “The elements every successful brand ambassador program needs \#semrushchat", available at: https://www.semrush.com/blog/the-elements-everysuccessful-brand-ambassador-program-needs-semrushchat/ (accessed 5 January 2020).

Tajfel, H. (1979), "Individuals and groups in social psychology”, British Journal of Social and Clinical Psychology, Vol. 18, pp. 183-190.

Urbaniak, M. (2016), “What are brand ambassadors and why are they important?”, available at: https://www.meltwater.com/blog/what-are-brand-ambassadors-and-why-are-theyimportant/\# (accessed 5 January 2020).

Wimmer, R.D. and Dominick, J.R. (2006), Mass Media Research, $8^{\text {th }}$ ed., Thomson Wadsworth, Belmont, CA. 
Xiong, L., King, C. and Piehler, R. (2013), “'That's not my job’: Exploring the employee perspective in the development of brand ambassadors", International Journal of Hospitality Management, Vol. 35, pp. 348-359. 
Table 1

Brand Ambassador Participants

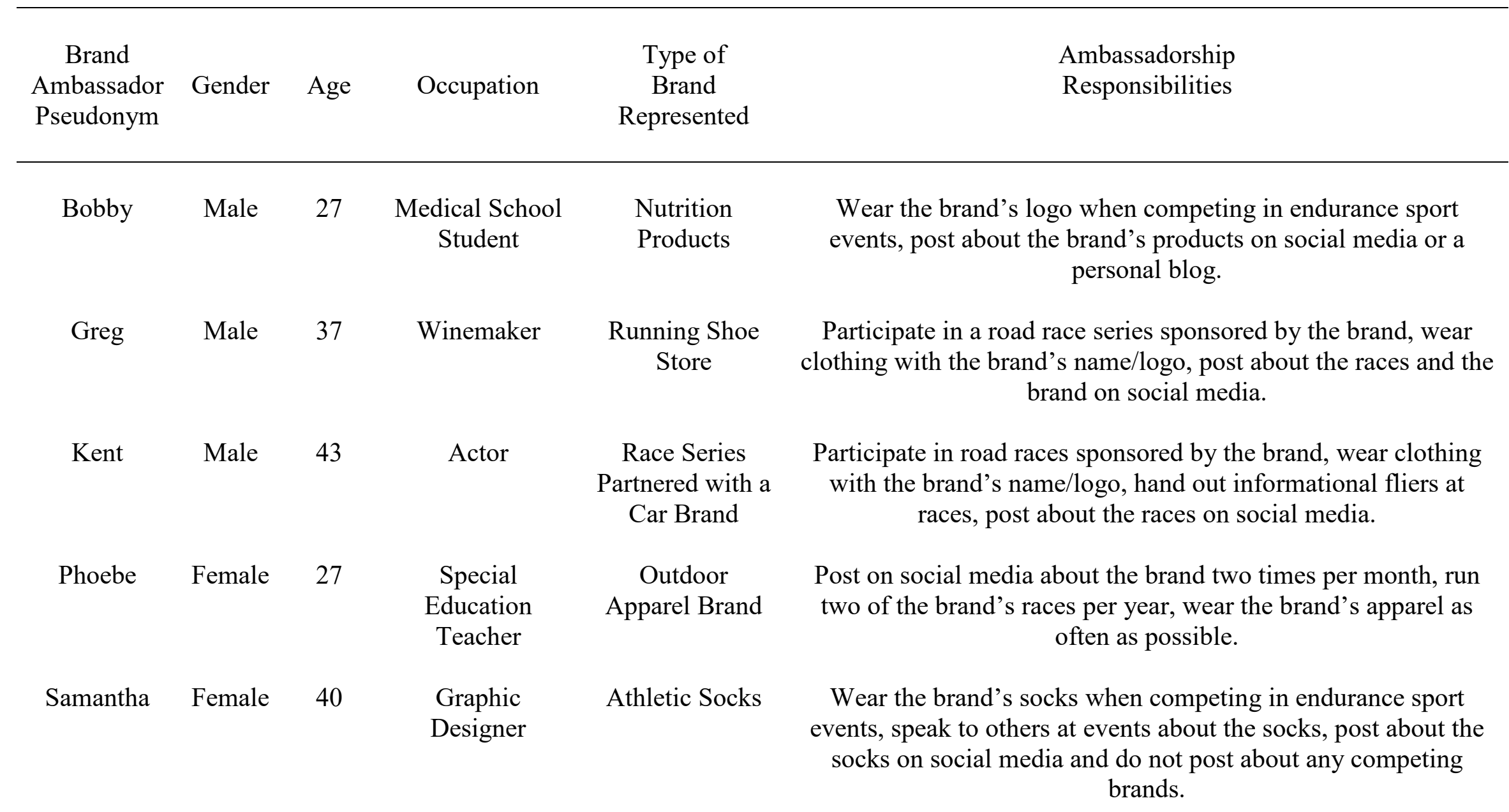


Sarah Female 29 Dietitian $\quad \begin{gathered}\text { Coffee Brand } \\ \text { Affiliated with }\end{gathered}$ Athletes
Post on social media about the brand at least two times per month, assist in promoting the brand to coffee shops and sport shops in the ambassador's local area by giving them samples. 
Table 2

Brand Ambassador Participant Themes

Category Theme Example of the Theme

Participation motives $\quad$ Free items

Feeling of pride or being special

Affiliation with a brand that aligned with personal characteristics

Whether personal expectations were met

ambassadors' experiences
"I applied for the ambassador program because I saw what other people [ambassadors] had and ... I wanted free stuff." -Bobby

"I' $m$ in the public eye now. At a recent race three or four people came up to me just based on my sock and said they knew who I was and 'I love your socks' and stuff like that." -Samantha

"I've always gravitated towards small organizations and helping them grown in some sort of way, that's just been my niche for the last, I don't even know how long, since literally before even high school. That's just something that I've always been interested in and that's a big reason why I want to be with this [brand], too, to watch them grow and support in any little way or big way as possible." -Phoebe

“There's nothing lost [by participating]. You're going to participate [in road races] anyway, and it didn't really bother me wearing someone else's name on your shirt or agreeing to any of the terms of it and I was very pleased to not actually be spending my money on shoes that otherwise, I was going to purchase anyway." -Greg

Perceived relationship with the brand
"I just like the small-town feel of it. The community of these guys. Everything's pretty cool with them." -Kent 
Perceived personal value to the brand

Perceived amount of work involved

Ambassadors' perceived best aspects of participation

Ambassadors' perceived challenges to participation
Sense of community

Free products and/or discounts

Not wanting to come across as a marketer or salesperson

Self-inflicted pressure to perform a certain way for the brand

Pressure to purchase products
"It was a very low-pressure situation and anytime I interacted with [brand owner] or saw him out at a race he was very friendly and seemed very appreciative that I was wearing the shirt with his store's name on it." -Greg

"It's not really a huge commitment, but just that exposure for them on social media is mainly what they want you to do." -Sarah

"[Getting to know the other ambassadors] is interesting because I get to be a little bit more personal with a lot of these athletes and I get to see inside the heads of like, what a lot of other people think. How really ultra-competitive people are versus how they're just out there to have a good time."-Greg

"We get a bag of their coffee every month, which is nice ... you get a hydro-flask coffee mug thing with their brand on it, and a t-shirt and a hat as well, and you also get $20 \%$ off of their online site. I'm definitely happy with the incentives." -Sarah

"I don't want to become a robot, just selling something. I am a person and while I'm happy to share my experiences with the product, I'm not bought and sold by that product. You know what I mean? So, I guess that would be my challenge, it's just sort of a personal challenge." -Samantha

"I would say the most challenging for me has been the requirement for racing. Like, I want to get on to the racing as quick as possible, but I have, like a delay in my training here. So, it's kind of like, is the race [requirement for ambassadorship] worth it over my health?"-Phoebe

"From what I've learned, [my ambassador program] is not actually giving me anything. It's just, like, a discount, but the discount ends up being not that much, and I don't want to buy anything." -Bobby 
Lack of clear communication from the brand
"I keep wondering, you know they say, 'Usually in the spring and in the fall we'll send out a couple pairs of socks to you for free', but they don't really define that at all, and so, I feel myself wondering, 'Well should I buy that, or are they going to send it to me?' You know? And are they going to tell me that in advance because I certainly don't need two pairs. So, a little definition and better communication there would be nice, I think." -Samantha 